www.jmscr.igmpublication.org

Impact Factor (SJIF): 6.379

Index Copernicus Value: 71.58

ISSN (e)-2347-176x ISSN (p) 2455-0450

crossref DOI: https://dx.doi.org/10.18535/jmscr/v6i5.134

Journal Of Medical Science And Clinical Research

\title{
Intra-Axial Neoplasms: Conventional Versus Advanced MRI
}

\author{
Authors \\ Dr Savitri Bhagat ${ }^{1}$, Dr Subhasish Panda ${ }^{2}$, Dr Shamimun Nisa ${ }^{3}$, Dr Braja Bihari Panda ${ }^{4}$, \\ Dr Subhashree Dash ${ }^{5}$, Dr Bararuchi Dash ${ }^{6}$ \\ ${ }^{1}$ Prof \& HOD, Dept of Radiodiagnosis, VIMSAR, Burla, India \\ ${ }^{2,5} \mathrm{PG}$ Student, Dept of Radiodiagnosis, VIMSAR, Burla, India \\ ${ }^{3}$ Prof \& HOD, Dept of Radiodiagnosis, MKCG, Berhampur, India \\ ${ }^{4}$ Assoc. Prof, Dept of Radiodiagnosis, VIMSAR, Burla, India \\ ${ }^{6}$ Prof \& HOD, Dept of Radiodiagnosis, Balasore, India \\ Corresponding Author \\ Dr Subhasish Panda \\ PG Student, Dept of Radiodiagnosis, VIMSAR, Burla, India \\ Email: drsubhasishpanda15@gmail.com
}

\begin{abstract}
Introduction: Brain tumors are the second leading cause of cancer related deaths in children and young adults, being common among all age groups. Diagnosis of intraxial brain tumors is very crucial since they are usually very advanced at the time of diagnosis. MRI, with the advent of advanced modalities such as Diffusion Weighted Imaging and Magnetic Resonance Spectroscopy, has gained an ever-increasing multifaceted role in the diagnosis of brain tumors. The role of conventional and advanced MRI in the diagnosis of intra-axial neoplasms need to be ascertained.

Materials and Methods: This is a prospective observational study undertaken over a period of two years on 52 patients evaluated by MRI with the aim to evaluate the characteristic MR findings of various intra-axial supratentorial neoplasms and to assess the additive role of advanced imaging in its diagnosis.

Results: The most commonly encountered neoplasm was high grade glioma followed by metastases. Diagnostic accuracy of MRI was $80.7 \%$ and upon addition of advanced imaging it was $94.2 \%$.

Conclusion: Advanced MR imaging modalities should be mandatory for evaluation of intraaxial mass lesions. Keywords: diffusion weighted, magnetic resonance perfusion, spectroscopy, enhancement.

\section{Introduction}

Intracranial neoplasms are on the rise in recent times. Most brain tumors are not diagnosed until after symptoms appear and hence are usually advanced at the time of diagnosis. Early diagnosis of the tumors helps in effective management of the deadly disease and save life. This requires prompt exclusion of other conditions which can simulate

radiological appearance of space-occupying lesions like abscesses, demyelinating disease, encephalitis and vascular malformations ${ }^{(1)}$.

The most effective and common imaging tool for diagnosing supratentorial (located above tentorial attachment of brain) intraaxial (located within the brain parenchyma) brain tumors is Magnetic Resonance Imaging (MRI) ${ }^{(2)}$. Conventional MRI techniques include $\mathrm{T} 1$ and $\mathrm{T} 2$ Weighted imaging
\end{abstract}




\section{JMSCR Vol||06||Issue ||05||Page 855-859||May}

with Gadolinium enhancement which provide anatomical localisation of the tumors. However, with this modality the distinction between various tumor types is not often possible.

Recently, with the advent of advanced MR imaging modalities such as Diffusion Weighted imaging, Spectroscopy and Perfusion imaging, MRI has gained an evolving multifaceted role in the accurate pre-operative evaluation with determination of histologic grade of tumors.

\section{Materials and Methods}

This was a Prospective Observational Study conducted on patients referred to the Dept. of Radiodiagnosis, VIMSAR, Burla, for diagnosis of suspected intracranial intraxial neoplasm. The study period was from October 2015 to September 2017 and all such patients of all ages and both sexes were included in the study.

The different types of MRI was performed on the patients including advanced MR imaging modalities such as Diffusion Weighted imaging, Spectroscopy and Perfusion imaging. The diagnostic Accuracy of different parameters of MRI was evaluated and correlated with biopsy.

\section{Results}

Fifty two patients were diagnosed with Supratentorial Intraaxial Neoplasms in the study period. The most commonly encountered neoplasm was Glioblastoma (4.6\%) followed by Metastases. Males were more commonly involved.

Table 1. Demographic Profile of Patients with Supratentorial Intra-axial Neoplasms

\begin{tabular}{|l|c|c|c|c|}
\hline Tumor Grade & $15-79$ & 12 & 6 & 18 \\
\hline $\begin{array}{l}\text { High } \\
\text { Astrocytic }\end{array}$ & $31-77$ & 7 & 8 & 15 \\
\hline Metastases & $4-8$ & 1 & 1 & 2 \\
\hline PNET Grade & $19-54$ & 6 & 5 & 11 \\
\hline $\begin{array}{l}\text { Low } \\
\text { Astrocytic }\end{array}$ & 17,40 & 1 & 1 & 2 \\
\hline Ependymoma & 58,66 & 2 & & 2 \\
\hline Lymphoma & 21 & 1 & & 1 \\
\hline Ganglioglioma & 5 & & 1 & 1 \\
\hline Astroblastoma & & 30 & 22 & 52 \\
\hline Total & & &
\end{tabular}

High grade astrocytoma was most common intraaxial neoplasm in our study. It most often occurred within 15 to 79 years. It was more prevalent in males.

Table 2. Contrast Enhancement Pattern of Supratentorial Intraxial Neoplasms on MRI.

\begin{tabular}{|l|c|c|c|c|c|}
\hline Tumor & $\begin{array}{c}\text { No } \\
\text { enhance } \\
\text { ment } \\
\text { us }\end{array}$ & $\begin{array}{c}\text { Hom } \\
\text { ogeno }\end{array}$ & $\begin{array}{c}\text { Inhomo } \\
\text { genous }\end{array}$ & $\begin{array}{c}\text { Ring- } \\
\text { like/ } \\
\text { Perip } \\
\text { heral }\end{array}$ & Total \\
\hline $\begin{array}{l}\text { High Grade } \\
\text { Glioma }\end{array}$ & 3 & 5 & 10 & 18 \\
\hline Metastases & & 5 & & 10 & 15 \\
\hline PNET & 11 & & 2 & & 2 \\
\hline $\begin{array}{l}\text { Low Grade } \\
\text { Glioma }\end{array}$ & & 2 & & & 11 \\
\hline $\begin{array}{l}\text { Ependymom } \\
\text { a }\end{array}$ & & & 1 & & 2 \\
\hline Lymphoma & & & 9 & 22 & 52 \\
\hline $\begin{array}{l}\text { Ganglioglio } \\
\text { ma }\end{array}$ & 14 & 7 & & & 1 \\
\hline $\begin{array}{l}\text { Astroblasto } \\
\text { ma }\end{array}$ & & & & & 1 \\
\hline Total & & & & & \\
\hline
\end{tabular}

Ring like enhancement was most often found in high grade gliomas, metastasis and ependymoma. Low grade gliomas did not show any enhancement in all cases. Ganglioglioma and astroblastoma demonstrated inhomogenous enhancement.

Table 3. ADC Values of selected neoplasms.

\begin{tabular}{|l|c|c|c|}
\hline ADC & $\begin{array}{c}\text { High Grade } \\
\text { Glioma } \\
\left(\times 10^{-3}\right. \\
\left.\mathrm{mm}^{2} / \mathrm{sec}\right)\end{array}$ & $\begin{array}{c}\text { Low Grade } \\
\text { Glioma }\left(\times 10^{-3}\right. \\
\left.\mathrm{mm}^{2} / \mathrm{sec}\right)\end{array}$ & $\begin{array}{c}\text { Lymphoma } \\
\left(\mathrm{x} 10^{-3}\right. \\
\left.\mathrm{mm}^{2} / \mathrm{sec}\right)\end{array}$ \\
\hline Minimum & 0.99 & 1.23 & 0.63 \\
\hline Mean & 1.15 & 1.48 & 0.66 \\
\hline
\end{tabular}

Lower ADC values were seen in lymphoma as compared to gliomas.

Table 4. MR Spectroscopy acquisition

\begin{tabular}{|l|c|c|c|}
\hline Tumor & Total & $\begin{array}{c}\text { Cho/Cr }> \\
1.8\end{array}$ & $\begin{array}{c}\text { Lactate } \\
\text { elevation }\end{array}$ \\
\hline High Grade Glioma & 18 & 15 & 11 \\
\hline Low Grade Glioma & 11 & 6 & 0 \\
\hline
\end{tabular}

Lactate elevation was a consistent feature in high grade gliomas. 


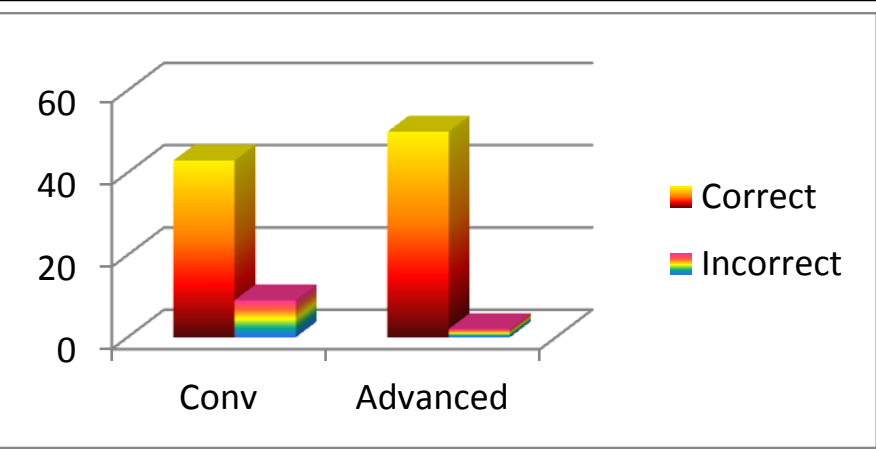

Fig 1. Comparison of Diagnostic Accuracy of Conventional and Advanced MRI.

Gadolinium enhancement alone has low sensitivity and specificity in the evaluation of intraaxial neoplasms with difficult differentiation of various tumor types. Advanced MRI techniques helps in improving accuracy of diagnosis.

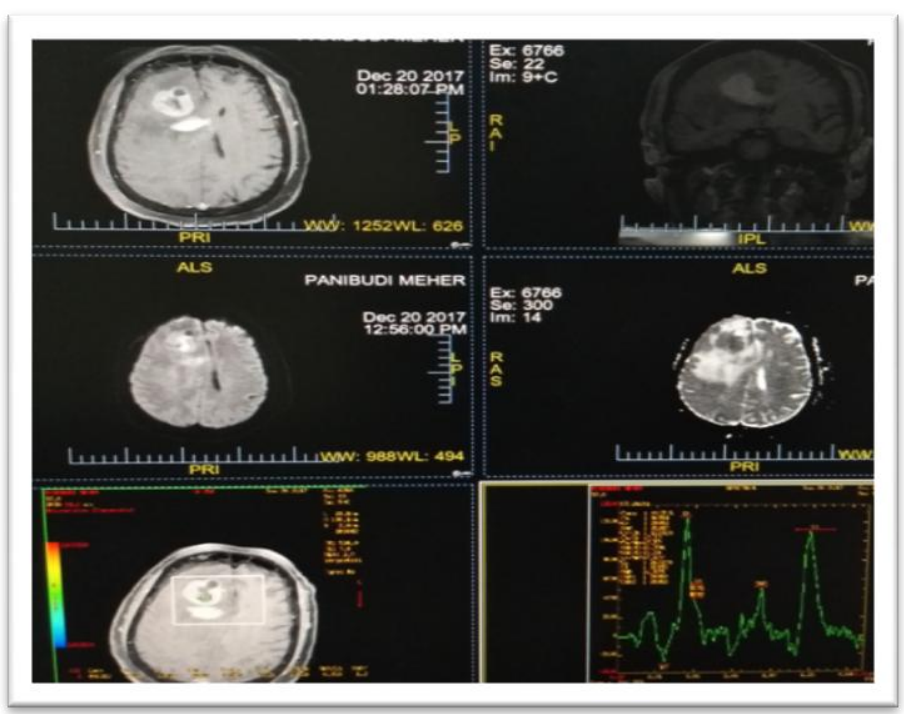

Fig 2. . Image on upper row showing axial and coronal T1 post contrast- a heterogeneously enhancing right frontal lobe mass extending into the corpus callosum with surrounding edema. Middle row shows areas of diffusion restriction. Lower row - MRS of the lesion - elevated Choline, lipid lactate and diminished NAA peak. This was a case of glioblastoma multiforme.

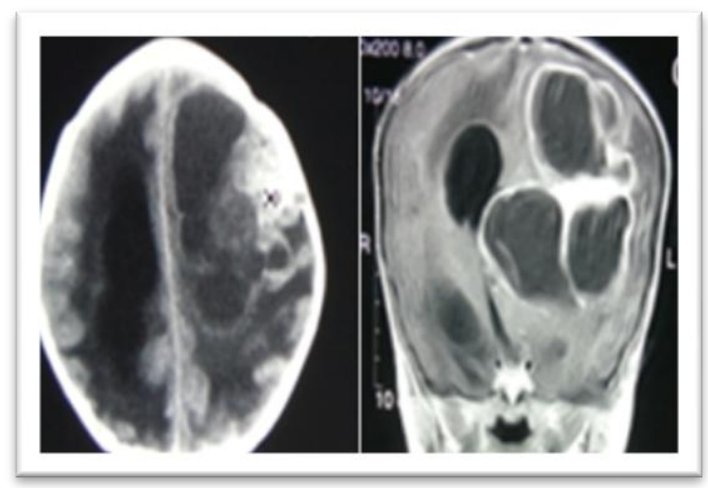

Fig 3. Axial and coronal CT post contrast image showing a heterogenous solid cystic lesion solid part taking avid enhancement. Marked adjacent edema also evident.

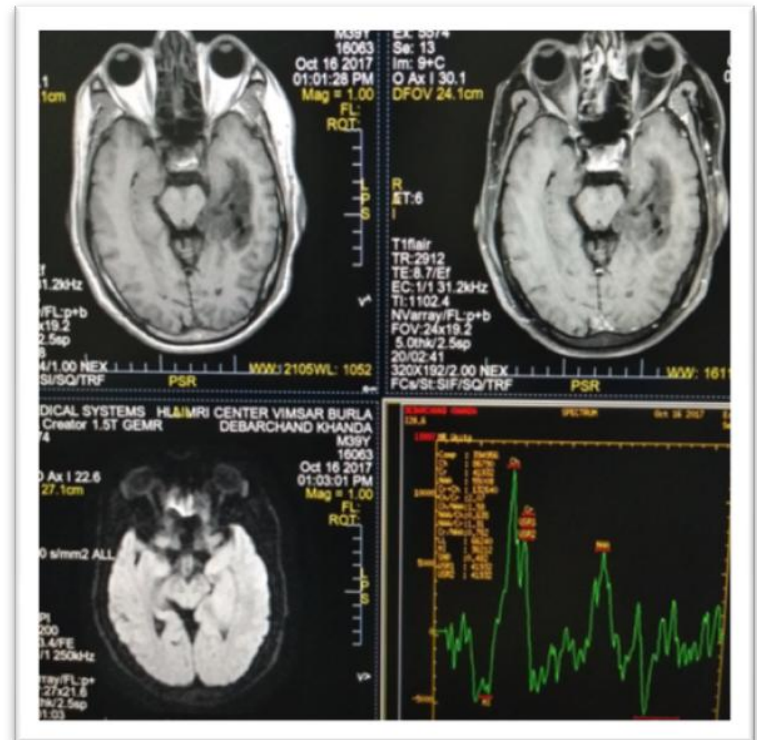

Fig 4. Upper row showing heterogenously hypointense lesion in left temporal lobe not taking enhancement on contrast administration. Lower row: No diffusion restriction; MRS - MI/Cr ratio >0.6.

\section{Discussion}

In T1 weighted images most tumors were hypointense $(37(49.3 \%))$ or isointense $(28(37.3 \%))$. Mixed intensity was seen in 4 cases of High Grade Astrocytic tumors, all of which were hemorrhagic.

Most of the tumors showed hyperintensity in T2 weighted MR images (46 (61.3\%)). This was consistent with Anna Zimny et $a l^{(3)}$. Most of the lymphomas were hypointense in T2 weighted MRI which exactly corroborated to the study conducted by Schwingel $R$ et al ${ }^{(4)}$. 
Also 39 out of 52 patients $(75 \%)$ revealed $\mathrm{Gd}$ enhancement.

Both Ependymomas diagnosed in our study were located adjacent to the cortical surface, which is characteristic according to Schwartz TH et $a l^{(5)}$. They showed complete ring like enhancement.

There was no significant enhancement in three out of 18 high grade gliomas. This was well correlated with JN Scott et al found upto one-third of cases of High Grade/Malignant Gliomas without enhancement on imaging ${ }^{(6)}$.

Patchy enhancement was evident in one Low Grade Glioma. According to Johann Palud et al diffuse low grade gliomas can rarely show patchy, heterogenous, faint enhancement ${ }^{(7)}$.

Among gliomas, high grade gliomas depicted lower ADC values than low grade gliomas. In comparison , $0.82+/-0.3$ and $1.15+/-0.3$ were the min. ADC values for high and low grade gliomas respectively in a study by Osama et al (lower than our study) (8). This has been attributed to differences in MRI equipment and $b$ values used. In the present study, lower ADC values were seen in lymphoma as compared to gliomas due to their higher cellularity.

A Cho/Cr ratio cut-off of 1.8 was used to distinguish between low grade and high grade gliomas. This, when combined with lactate peak led to a higher diagnostic accuracy for high grade gliomas (97\%).

For low grade gliomas, $\mathrm{MI} / \mathrm{Cr}$ ratios were used and values of 0.6 or more were encountered in $100 \%$ of the cases in keeping with studies by Bartha and Ruggieri PM et $\mathrm{al}^{(9,10)}$. In fact, the range of values obtained in the present study was more specific than that carried out by Ruggieri PM et $\mathrm{al}^{(10)}$.

MR perfusion values of $r \mathrm{CBV}$ (mean and range) calculated in case of gliomas demonstrated significantly higher values in case of high grade gliomas compared to low grade gliomas. This correlated well with a study by Hakyemez et $\mathrm{al}^{(11)}$.

Finally, the difference between the diagnostic accuracy of Conventional MRI alone and this when combined with advanced modalities for supratentorial intraaxial neoplasms, was found to be statistically significant ( $\mathrm{p}<0.05$ ).

\section{Conclusion}

Advanced MRI modalities provide additional information which make MRI a comprehensive tool in conclusive diagnosis of Supratentorial Intraaxial Tumors. Advanced MR imaging is superior to Conventional MRI in the identification of the type of neoplasm and ascertaining its grade; when compared to Conventional imaging and hence, should be mandatory for evaluation of intraaxial mass lesions.

\section{References}

1. Anjana Trivedi, Jay Thakkar, Maulik Jethva, Ishita Virda.CT \& MRI Evaluation of Brain Tumour \& Tumour like Conditions. International Journal of Scientific Research. Volume 6 Issue 3, Mar 2017.730-734.

2. Gado MH, Phelps ME, Coleman RE. An extravascular component to contrast enhancement in cranial computed tomography. Part I: the tissue-blood ratio of contrast enhancement. Radiology 1975;117:589-593.

3. Anna Zimny et al. Intracranial Lesions with Low Signal Intensity on T2- weighted MR Images - Review of Pathologies. Pol J Radiol. 2015; 80: 40-50.

4. Schwingel R, Reis F, Zanardi VA, et al. Central nervous system lymphoma: magnetic resonance imaging features at presentation. Arq Neuropsiquiatr. 2012;70 (2):97-101

5. Schwartz TH, Kim S, Glick RS, Bagiella E,et al. Supratentorial ependymomas in adult patients. Neurosurgery1999;44(4):721-31.

6. JN Scott et al. How often are non-enhancing supratentorial gliomas malignant? A population study. Neurology 2002; 59(6): 947- 9.

7. Johann Palud et al. Prognostic significance of imaging contrast enhancement for WHO grade II gliomas. Neuro Oncol. 2009 Apr; 11(2): 176-182.

8. Osama Mohammed Ebied et al. Minimum Apparent Diffusion Coefficient (ADC) Value in Differentiation of High and Low 
Grade Gliomas , Does it Make a Difference?

Cancer Prev Curr Res 6(1):00193.

9. Bartha R, Megyesi JF, Watling CJ. Low

Grade Glioma: Correlation of short echo time H1-MR Spectroscopy with Na23 MR imaging. AJNR Am J Neuroradiol 29:464470,2008.

10. Ruggieri PM. Practical MR spectroscopy in paediatric neuroradiology. Atlanta, April 2000.

11. Hakyemez et al. High-grade and low-grade gliomas: differentiation by using perfusion MR imaging. Clin Radiol. 2005 Apr;60(4): 493-502. 